\title{
O fenômeno das lan houses
}

\begin{abstract}
APESAR DE UM CRESCIMENTO SIGNIFICATIVO NA FATIA DA POPULAÇÃO BRASILEIRA COM ACESSO À INTERNET NOS ÚLTIMOS CINCO ANOS. A INCLUSÃO DIGITAL AINDA É UM GRANDE DESAFIO DO GOVERNO E DA INICIATIVA PRIVADA. NESSE CONTEXTO, AS LAN HOUSES DESEMPENHAM UM PAPEL FUNDAMENTAL
\end{abstract}

Por Alexandre Barbosa e Juliano Cappi

Embora a expansão do uso da internet no Brasil nos últimos anos tenha sido significativa, passando de 30,5 milhões em 2005 para, aproximadamente, 50 milhões em 2008, o país ainda tem um longo caminho a percorrer para promover a inclusão digital de parcela considerável da população.

Uma das políticas promovidas pelo governo federal para contornar essa situação foi a criação de centros públicos de acesso gratuito à internet, os telecentros, como são conhecidos. Seu foco é atender a população carente, especialmente as camadas C, D e E, bem como as áreas rurais, onde há pouca ou nenhuma infraestrutura tecnológica. Os telecentros não atingem mais do que $3 \%$ da população e essa situação permaneceu assim entre 2005 e 2008. Entretanto, esse número representa cerca de dois milhões de brasileiros em áreas remotas do país e das classes mais baixas da população.

Os centros públicos de acesso pago, conhecidos como lan houses, revelaram-se fundamentais para o crescimento do uso da internet no Brasil, superando, inclusive, o número de aces- sos via domicílio. Os dados da edição 2008 da Pesquisa sobre o uso das TICs no Brasil - TIC Domicílios, realizada pelo Comitê Gestor da Internet no Brasil, revelam que as lan houses são o principal local de acesso à internet, apontado por $48 \%$ dos brasileiros. Em segundo lugar, figuram os domicílios, com 42\%; a casa de outras pessoas e o trabalho, com 22\% e 21\%, respectivamente. Na área rural, a sua importância no processo de inclusão digital é ainda maior: 58\% dos internautas acessam a internet pelas lan houses. Como consequência, elas cumprem um papel destacado no processo de inclusão digital em nosso país.

INTERNET NO BRASIL. Segundo a Pesquisa TIC Domicílios, um quarto dos domicílios brasileiros (25\%) possui computadores e apenas $18 \%$ possuem acesso à internet. A pesquisa ainda identificou que $71 \%$ dos lares com computador possuem acesso à internet. Essa diferença denota que, dos 14 milhões de domicílios com computador, quatro milhões não possuem acesso à internet. 


\section{GRÁFICO 1 - Proporção dos domicílios com computador e internet (Percentual sobre o total de domicílios)}

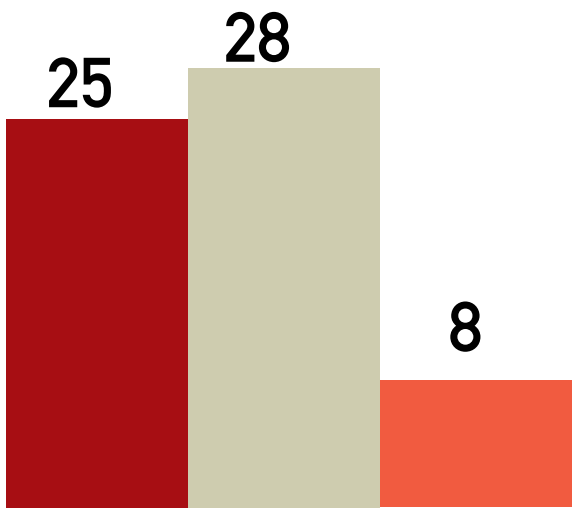

computador

Fonte: Pesquisa sobre o uso das TICs no Brasil

A comparação entre os domicílios nas áreas urbana e rural evidencia uma expressiva diferença na disseminação dessas tecnologias: enquanto 28\% dos domicílios nas áreas urbanas possuem computador, nas áreas rurais a incidência é de apenas $8 \%$. Com relação ao acesso à internet, a diferença também chama a atenção: enquanto nas áreas urbanas a disseminação do acesso chega a 20\% dos domicílios, nas áreas rurais esse percentual cai para 4\% (ver Gráfico 1).

O perfil de uso do computador e da internet é muito semelhante com relação às variáveis sociodemográficas. Conforme a renda, a classe social e o grau de escolaridade aumentam, maior é a proporção de usuários. Entre os usuários com nível superior, o acesso à internet chega a 83\%, ao passo que tal proporção é de apenas 7\% entre os analfabetos e pessoas que têm somente educa-

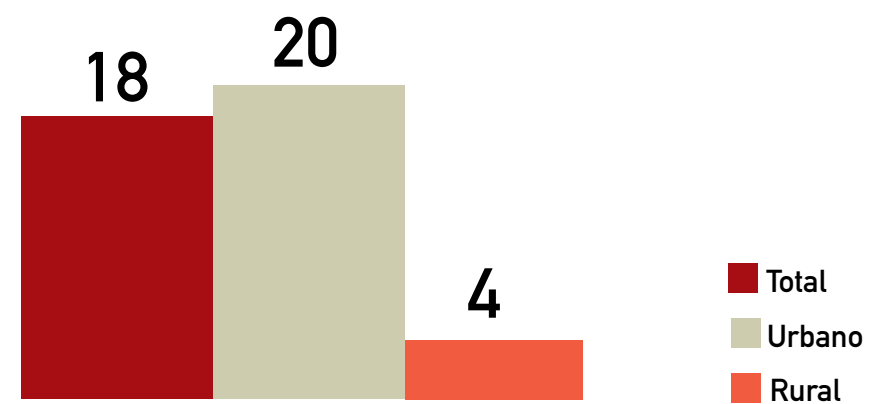

internet

ção infantil. No que tange à renda, na faixa de até um salário mínimo, o percentual de usuários de internet é de $10 \%$, contra $81 \%$ na faixa de 10 ou mais salários. A diferenciação por classe social guarda a maior discrepância entre suas categorias, na medida em que há uma diferença de 76 pontos percentuais entre a classe A (89\%) e as classes D e E (13\%).

Outra importante característica relacionada ao perfil do usuário da internet é que, apesar de 38\% da classe $C$ ter acessado a internet nos últimos três meses, essa proporção representa mais da metade do número de usuários totais, ou seja, 54\% (barras vermelhas do Gráfico 2). Isso denota que, apesar de a disseminação do uso da internet ser relativamente baixa nessa classe (se compararmos com os $89 \%$ da classe A), numericamente, mais da metade dos internautas encontra-se na classe $\mathrm{C}$. 
Em casa

- Centro público de acesso pago

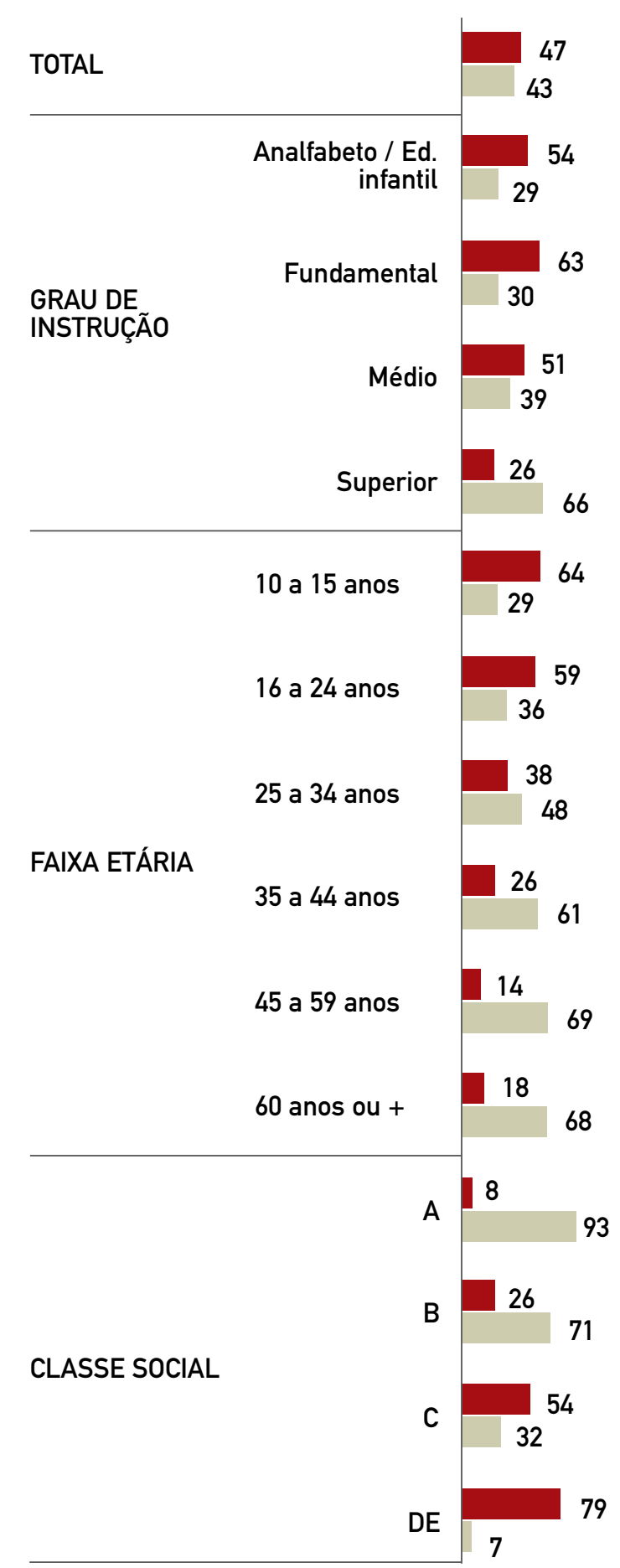

Fonte: Pesquisa sobre o uso das TICs no Brasil
INCLUSÃO DIGITAL. A pesquisa também identificou que, para 54\% dos brasileiros, a principal barreira para o acesso à internet é o custo (ver Gráfico 3). O segundo motivo mais citado para justificar a ausência de acesso à rede em domicílio é o fato de existir a disponibilidade de acesso em algum outro lugar alternativo (21\%), seguido da "falta de interesse" (18\%) e "falta de disponibilidade na área" (17\%). Embora esse último fator tenha sido identificado como a quarta resposta no ranking dos motivos para a falta de acesso à internet no total dos domicílios brasileiros, a pesquisa revela que, na área rural, esse fator tem uma importância mais significativa. Nesses locais, a falta de disponibilidade é percebida como o segundo motivo mais relevante para a ausência do acesso à internet nos lares, representando $27 \%$ das declarações.

O baixo preço cobrado pelas lan houses para acesso à internet contribui para que parcela significativa da população, que não consegue arcar com o custo do acesso no domicílio, use a rede através desses locais. Os telecentros também têm um papel importante nesse processo, visto que oferecem acesso gratuito, em regiões onde a iniciativa privada muitas vezes não tem interesse nem condições de explorar, configurando como única alternativa para que milhares de brasileiros tenham acesso à internet.

ALIANÇA PÚBLICO-PRIVADO. Em nossa visão, a inclusão digital da população brasileira depende de um modelo de gestão adequado ao perfil continental e heterogêneo do país. Nesse modelo, as lan houses e os telecentros desempenham um papel fundamental para o sucesso de programas voltados à inclusão digital. A construção de polí- 


\section{GRÁFICO 3 - Motivos para a falta de acesso à internet no domicílio (percentual sobre o total de domicílios que possuem computador, mas não têm acesso à internet)}

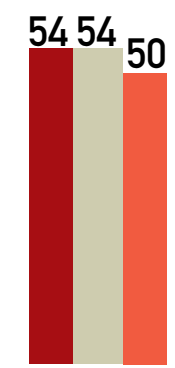

Custo elevado / Tenho acesso Não tenho como pagar

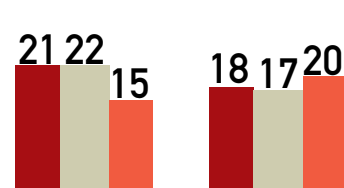
em outro lugar necessidade

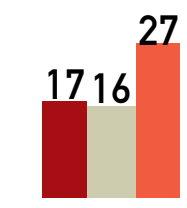

Falta de disponibilidade não vale a pena na área
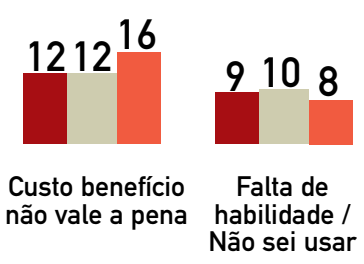

Falta de habilidade / Não sei usar

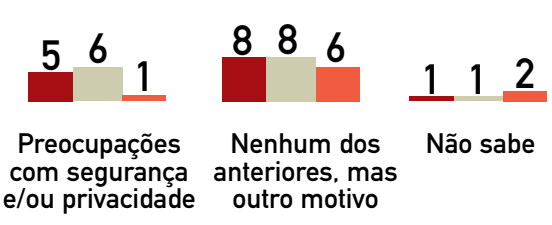

Fonte: Pesquisa sobre o uso das TICs no Brasil

ticas públicas efetivas requer um diálogo aberto entre o governo, como representante legítimo da sociedade e gestor dos interesses públicos, a iniciativa privada, na defesa de seus interesses e na formação de novos mercados, e a sociedade civil, que representa os interesses coletivos.

Para finalizar, é importante dizer que, apesar das dificuldades, o governo brasileiro tem desenvolvido iniciativas para ampliar a inclusão digital. Além da criação de telecentros em locais onde muitas vezes a iniciativa privada não tem condições ou mesmo interesse de explorar, foi criado o Programa "Computador para Todos", o qual incentiva a indústria e o varejo na oferta dirigida de computadores à população de baixa renda com preços subsidiados e linha de financiamento específica, além da isenção dos impostos PIS e COFINS. Uma terceira iniciativa, que começa a ser implementada em alguns estados, é a redução do custo do acesso à internet através de incentivos fiscais para a população de baixa renda - por exemplo, a redução do ICMS. Certamente, iniciativas como estas são decisivas na ampliação do acesso à internet no Brasil. Outra iniciativa em discussão no governo é o Plano Nacional de Banda Larga. Esse plano tem como meta chegar a 2014 com 90 milhões de acessos de banda larga por meio de uma parceria público-privado. A ideia baseiase na lógica de que o governo deve prover parte da infraestrutura para fomentar o acesso à internet necessária no país, complementando assim a infraestrutura existente.

ALEXANDRE BARBOSA, gerente do Centro de Estudos sobre as TICs, alexandre@nic.br JULIANO CAPPI, analista de Informações do CETIC.br, juliano@nic.br 